\title{
Technical efficiency of health-care systems in selected middle-income countries: an empirical investigation
}

\author{
Heba Nassar, Hala Sakr, Asmaa Ezzat and Pakinam Fikry \\ Faculty of Economics and Political Science, Cairo University, Giza, Egypt
}

Received 10 March 2020

\begin{abstract}
Purpose - This paper aims to evaluate the technical efficiency of the health-care systems in 21 selected middle-income countries during the period (2000-2017) and determine the source of inefficiency whether it is transient (short run) or persistent (long run).

Design/methodology/approach - The study uses the stochastic frontier analysis technique through employing the generalized true random effects model which overcomes the drawbacks of the previously introduced stochastic frontier models and allows for the separation between unobserved heterogeneity, persistent inefficiency and transient inefficiency.

Findings - Persistent efficiency is lower than the transient efficiency; hence, there are more efficiency gains that can be made by the selected countries by adopting long-term policies that aim at reforming the structure of the health-care system in the less efficient countries such as South Africa and Russia. The most efficient countries are Vietnam, Mexico and China which adopted a social health insurance that covers almost the whole population with the aim of increasing access to health-care services. Also, decentralization in healthcare has assisted in adopting health-care policies that are suitable for both the rural and urban areas based on their specific conditions and health-care needs. A key success in the implementation of the adopted long-term policies by those countries is the continuous monitoring and evaluation of their outcomes and comparing them with the predefined targets and conducting any necessary modifications to ensure their movement in the right path to achieve their goals.

Originality/value - Although several studies have evaluated the technical efficiency both across and within countries using non-parametric (data envelopment analysis) and parametric (stochastic frontier analysis) approaches, to the best of the authors' knowledge, this is the first attempt to evaluate the technical efficiency of selected middle-income countries during the period (2000-2017) using the generalized true random effects stochastic frontier analysis model.
\end{abstract}

Keywords Technical efficiency, Stochastic frontier analysis, Health-care systems,

Transient efficiency, Persistent efficiency, Middle-income countries

Paper type Research paper

\section{Introduction}

The positive impact of better health on the quality of life of individuals and their well-being, economic growth and sustainable development has made it an important topic with a great

(C) Heba Nassar, Hala Sakr, Asmaa Ezzat and Pakinam Fikry. Published in Review of Economics and Political Science. Published by Emerald Publishing Limited. This article is published under the Creative Commons Attribution (CC BY 4.0) licence. Anyone may reproduce, distribute, translate and create derivative works of this article (for both commercial and non-commercial purposes), subject to full attribution to the original publication and authors. The full terms of this licence may be seen at http://creativecommons.org/licences/by/4.0/legalcode

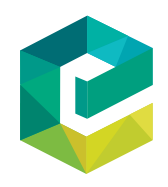

Review of Economics and Political Science pNo. 4,2020 Emerald Publishing Limited e-ISSN: 2631-3561 p-ISSN: $2356-9980$ DOI 10.1108/REPS-03-2020-0038 
REPS

5,4

\section{8}

interest for researchers and policy makers worldwide. Hence, improvement of the health status has become increasingly important both nationally and internationally, where it has been a part of the international development and sustainable development agendas represented in both the Millennium Development Goals and the 2030 Sustainable Development Goals.

In spite of the fact that many efforts are being exerted worldwide to enhance the organization and efficiency of the health-care sector and to ensure equitable access to healthcare services, the health-care sector is still suffering from critical challenges that need to be addressed; such as high prevalence of non-communicable diseases, increasing demand on health-care, limited financial resources available for expenditure on health-care, increasing costs of health-care services and fragmentation of health-care systems.

The 2000 World Health Report illustrated that there are three main goals for any healthcare system, which are improving health, increasing responsiveness to the legitimate demands of the population and ensuring that financial burdens are distributed equitably (World Health Organization, 2000). With the high population growth rates in developing countries and the increasing number of the ageing population in developed countries, the demand on health-care services has increased substantively. However, the continuous upsurge in the health-care costs resulting from the introduction of new health-care technologies and procedures in addition to the limited public financial resources available for expenditure on health-care have left the governments unable to meet the increasing health-care needs of the population.

In addition to that, the World Health Organization (WHO) estimated that around $20-40 \%$ of resources spent on health-care are underused by all health-care systems. Although this rate differs from one country to another, some countries are capable of getting more value for money compared to others represented in higher levels of coverage and better health outcomes. Health-care inefficiency mostly results from poor procurement, inefficient allocation and management of human and technical resources, fragmented financing and organization, lack of good governance and inappropriate use of medicines (Hamidi and Akinci, 2016; World Health Organization, 2010).

Accordingly, several studies were conducted with the aim of evaluating the technical efficiency of health-care systems, which is concerned with maximizing the health output in light of the limited physical and financial inputs available for the country to produce healthcare services (Asandului et al., 2014; Kim and Kang, 2014; Tandon et al., 2001; De Cos and Moral-Benito, 2011; Ravangard et al., 2014).

The efficiency of health-care systems shall ensure that the resources are being used in a way that maximizes the health outcomes in addition to increasing the confidence in the health-care system as the patients will be assured that their financial contributions are spent in the most suitable way to satisfy their health needs. Efficiency improvements shall also affect cost savings and facilitate expansion of health-care services to cover more people and offer more services (Cylus et al., 2016).

Achieving technical efficiency in health-care systems is of particular importance to middleincome countries in light of their limited financing resources and high dependency on out-ofpocket expenditure in addition to their continuous efforts to achieve universal health coverage and financial protection. Despite that, evaluating the technical efficiency of middle-income countries has not been of major concern in the previously conducted research (McIntyre, 2007).

Therefore, this paper aims at studying the technical efficiency of health-care systems in 21 middle-income countries which have been chosen in such a way that allows for constructing a relatively homogeneous sample despite their diverse economic, political and institutional structure. The 21 chosen countries satisfy at least 2 of the following criteria: 
global influence (middle-income countries that are a member of the G20), rapid economic transformation (middle-income countries that belong to the Dow-Jones and N-11 lists of emerging markets) and large internal market (middle-income countries classified as an emerging and developing country by the IMF).

The 21 countries are: Algeria, Argentina, Bangladesh, Brazil, China, Colombia, India, Indonesia, Iran, Malaysia, Mexico, Egypt, Pakistan, Peru, Philippines, Romania, Russia, South Africa, Thailand, Turkey and Vietnam.

The paper will be structured as follows. The first section reviews the prevailing literature on evaluating the technical efficiency in health-care. The second section briefly presents some stylized facts about middle-income countries. The third section describes the methodology and the data used. The fourth section displays the results. The last section concludes the paper with policy implications and data limitations.

\section{Literature review}

Efficiency has been a major concern for economists since 1951, when it was first introduced by Koopmans and Debreu. This concern has arisen due to the importance of efficiency as a performance measure for the production units. Also, it allows to evaluate not only the impact of the production inputs but also the impact of the surrounding environment (political, economic, social, institutional and legal) on productivity (Lovell, 1993).

Inefficiency of health-care systems occur due to two main reasons, the first of which is the misusage of health inputs in such a way that leads to producing health output less than the optimal level of output (technical inefficiency). The second reason is directing health inputs such as expenditure on health-care toward producing health outputs that are not priorities of the economy (allocative inefficiency).

Technical efficiency has been used extensively in evaluating the efficiency of health-care on both the micro and macro levels due to its ability in allowing for the evaluation of different units/systems and comparing between them, while the allocative efficiency has been most commonly used on the micro level by health technology assessment agencies to evaluate different treatments and determine their impact on maximizing health outputs taking their cost into consideration. Data limitations and the difficulty in valuing health inputs and outputs made it difficult to conduct an allocative efficiency analysis for healthcare systems from a macro perspective (Cylus et al., 2016). Therefore, the main focus of this paper will be on technical efficiency.

It is worth mentioning that there is no specific theory that explains efficiency in healthcare, as based on the previously introduced two main types of efficiency the health-care system or unit is viewed as a production function that transforms the health-care resources into health outputs. Then a comparison between different units or systems is conducted versus the most efficient ones to determine how efficient each unit or system is relative to the others and to the most efficient one.

On the micro level, technical efficiency was evaluated for hospitals and nursing homes (Wagstaff, 1989; Hofler and Rungeling, 1994; Zuckerman et al., 1994; Chirikos, 1998; Gerdtham et al., 1999; Kooreman, 1994; Lo et al., 1996; Magnussen, 1996; Street and Jacobs, 2002; Colombi et al., 2017). On the macro level, where the overall performance of the healthcare system is evaluated, different variables and different methodologies (including either non-parametric or parametric approaches or both) were used in addition to conducting the evaluation process within or across countries. Most studies used life expectancy or healthy life expectancy or infant mortality as the health output, while the health inputs usually included indicators on income, education and expenditure on health-care in addition to other
Technical
efficiency of
health-care
systems

269 
REPS

5,4

indicators that differed from one study to another (Popescu et al., 2014; Koku, 2015; Novignon and Lawanson, 2014; Kathuria and Sankar, 2005; Dhaoui, 2019).

In most of the studies, it was found out that total health expenditure per capita, income per capita and education had a positive impact on the health output in contrast to the out-ofpocket expenditure which affected the production of health negatively.

Most studies have used the non-parametric approach, where efficiency was evaluated across and within countries mainly through using the data envelopment analysis (DEA) technique. Regarding evaluating the technical efficiency across countries, Mirmirani and Lippmann (2004) investigated the technical efficiency of health-care systems in the G12 countries during the period (1991-1995), while Grosskopf et al. (2006) estimated the efficiency of the health-care system financing in achieving better health for 143 developed and developing countries in 1997. Through calculating multilateral health sector quantity and improvement indices, it was concluded that although the high levels of public healthcare financing had diminishing returns on the health status in the developed countries, it had a positive impact on the health status in the middle-income countries.

In 2010, Ryltseva (2010) evaluated the efficiency in the way through which health inputs are used by 12 countries of the former Soviet Union in 2003, where Russia and Belarus were found to be the most inefficient countries. She concluded that if the increase in expenditure on health-care is not accompanied with improvements in the socio-economic factors and the healthy lifestyle, that increase will not have any significant impact on the health status.

Also, Asandului et al. (2014) investigated the technical efficiency of the public health-care systems in 30 European countries in 2010 and Ravangard et al. (2014) evaluated the technical efficiency of the health-care systems in ten Economic Cooperation Organization countries during the period (2004-2010) where the impact of both inputs under and beyond the control of the health-care system on health outputs was evaluated. The study concluded that Turkey had the highest efficiency scores, while Turkmenistan had the lowest scores.

Furthermore, Kim and Kang (2014) evaluated the efficiency of the health-care systems of 170 countries from different geographical regions in 2007 using bootstrap DEA, and they reached that countries in Asia are generally more efficient than those in Europe, North America and Oceania. In 2015, Medeiros and Schwierz (2015) evaluated the technical efficiency of the health-care systems of the EU countries during the period (2003-2010) where they concluded that Belgium, Cyprus, Spain and France are the most efficient countries.

Dhaoui (2019) evaluated the technical efficiency of MENA countries in 1997, 2005 and 2014 using both an input and an output oriented approach. He concluded that Morocco, Qatar and Yemen were efficient health-care systems during the three years and that some countries can learn from others with higher efficiency scores and more expenditure on health-care is not necessarily the best solution for inefficiency.

Regarding evaluating technical efficiency within countries, Romania was found to be inefficient compared to another $26 \mathrm{EU}$ member states, while Greece was found to be the most efficient. Low expenditure on health-care, high rates of poverty and the mismanagement of funding directed toward health-care have led to the deterioration of health-care services, the worsening of health status and an increase in the migration of medical staff to developed countries, which led eventually to the inefficiency of the health-care system in Romania compared to other EU countries (Popescu et al., 2014).

In 2016, Amponsah and Amanfo (2016) evaluated the efficiency of the health-care system in Ghana from a regional perspective during the period (2001-2014) using DEA and the Malmquist total factor productivity index. The study concluded that eight of the ten regions were technically efficient and during the 13 years their performance enhanced mainly due to technological innovation. 
Also, the technical efficiency of the health-care system in Lebanon was evaluated during the period (2000-2015) where it was found that not only increasing expenditure on healthcare is needed to achieve efficiency but also technical and operational improvement must be maintained (Ibrahim and Daneshvar, 2018).

Several studies have used the parametric approach in evaluating the health-care system efficiency across and within countries using different model specifications of the stochastic frontier analysis technique. Tandon et al. (2001) attempted to evaluate the technical efficiency of national health-care systems in producing health-care for 191 countries from 1993 to 1997 using the fixed effects model. However, the efficiency of those systems was reevaluated over the same period in 2003 by Hollingsworth and Wildman (2003) where Aigner et al. (1977) model and the DEA were used in the estimation procedure. Also, the sample was stratified into OECD and non-OECD countries and only 140 countries were included in the analysis due to data limitations. This study revealed that it is important to group countries based on similar characteristics, as non-OECD countries showed more variation in efficiency compared to OECD countries; hence, different estimation models should be used to evaluate efficiency in different groups of countries.

The efficiency of the health-care systems of 76 countries from four different regions (Asia, Europe and Central Asia, Latin America and the Caribbean and the industrial countries) was evaluated by Jayasuriya and Wodon (2003) over the period (1990-1998) using the Battese and Coelli (1995) model. It was found that the health-care system efficiency was positively affected by the bureaucratic quality and urbanization, while it was not affected by corruption. Using the same methodology, Ogloblin (2011) evaluated the efficiency of the health-care systems of 78 countries and concluded that public expenditure on health-care and out-of-pocket expenditure play an important role in decreasing inefficiency.

De Cos and Moral-Benito (2011) evaluated the technical efficiency of the health-care systems of 29 OECD countries between 1997 and 2009 using the Schmidt and Sickles (1984) model and the DEA, where the results of both approaches were found to be different despite using similar variables. According to the DEA, the most efficient countries were Australia, Switzerland and Korea, while Japan, Switzerland and Sweden were found to be the most efficient countries according to the frontier model.

Novignon and Lawanson (2014) evaluated the technical efficiency of the health-care systems in Sub-Saharan Africa using the true random effects model during the period (2005-2011), while Karpa and Leśniowska (2014) evaluated the technical efficiency of the health-care systems of OECD countries using Aigner et al. (1977) and Meeusen and Van Den Broeck (1977) models. One of the main conclusions of those studies was that efficiency is not only related to increasing expenditure on health-care as is usually presumed, but to other variables as well such as the institutional framework of the country, population growth rate and per capita income. The same result was also reached by Koku (2015) who evaluated the technical efficiency of the health-care system in the ECOWAS sub-region during the period (2002-2011) using the Battese and Coelli (1995) model.

Although the USA is one of the largest spenders on health-care, it was considered as one of the least efficient countries among the OECD countries by the WHO in its 2000 report entitled Health systems: improving performance. However, Frogner et al. (2015) evaluated the efficiency of the US health-care system relative to 25 OECD industrialized countries using fixed effects and stochastic frontier models and concluded that it is not one of the least efficient countries as its health-care system was found to be of medium efficiency.

In addition to that, the technical efficiency of the health-care systems in 20 MENA countries was estimated during the period (1995-2012) using the Battese and Coelli (1988, 1992) models and the true random effects model. The inefficiency estimates of the former
Technical efficiency of health-care systems

271 
REPS

5,4

272

two models were different from those of the later which gave lower inefficiency estimates. This resulted from the fact that the true random effects model accounted for heterogeneity in contrast to the Battese and Coelli models that did not account for it and which led to its inclusion in the composed error term leading to higher inefficiency estimates. Also, it was found that Lebanon, Qatar and Morocco were the countries with the most efficient estimates on average in the three used models (Hamidi and Akinci, 2016).

Kathuria and Sankar (2005) evaluated the technical efficiency of the rural public healthcare systems of 16 states in India during the period (1986-1997) using a fixed effects model. They found out that despite the importance of health-care infrastructure represented by access to facilities and availability of skilled medical staff in achieving efficiency in healthcare in rural India, other environmental aspects are also essential such as access to sanitation, literacy and increasing awareness. Differences in those aspects among states have led to different efficiency levels.

It can be concluded that not only expenditure on health-care is an important determinant of the health-care system efficiency but also other socio-economic and institutional factors. However, the role played by those various factors varied among studies.

As only few studies have evaluated the technical efficiency of health-care systems in developing countries in relation to developed countries using the non-parametric approach only without a special focus on the middle-income countries, this study aims at evaluating the technical efficiency of the health-care systems of selected middle-income countries using the stochastic frontier analysis parametric technique. The stochastic frontier analysis has been chosen due to its advantage in separating between the effects of noise and inefficiency and which is violated in the non-parametric approach.

Also, the generalized true random effects model introduced by Kumbhakar et al. (2014) will be used in evaluating the technical efficiency, as it overcomes the drawbacks of the previously introduced stochastic frontier analysis models and allows for the separation between unobserved heterogeneity, persistent inefficiency and transient inefficiency. In other words, it allows not only for measuring inefficiency scores among the selected countries similar to previous studies but also for separating between persistent and transient inefficiency.

\section{Stylized facts}

Middle-income countries have witnessed significant improvements in their health outcomes over the past 30 years. Life expectancy at birth has increased from 64.1 years in 1990 to 71.7 years in 2017, with more improvement among females (74 years) compared to males (70 years). Similar enhancements have been witnessed in infant, neonatal and under-five mortality rates per 1,000 live births that declined from 69, 38.8 and 91.1 in 1990 to 29.3, 17.5 and 35.8 in 2018. Also, the maternal mortality ratio declined from 295 to 177 per 100,000 live births during the period (2000-2017). This has been accompanied by an increase in the percentage of births attended by skilled health staff from $63 \%$ in 2000 to $83 \%$ in 2014 .

A decline also occurred in the prevalence of undernourishment and underweight, where the former declined among the population from $16 \%$ in 2000 to $11 \%$ in 2017 , while the latter declined among the children under five years from $27 \%$ in 1990 to $14 \%$ in 2018. Improvements have been witnessed also in access to basic drinking water services and basic sanitation services where $91 \%$ and $73 \%$ of the population had access to both in 2017 compared to $81 \%$ and $49 \%$ in 2000 (World Bank, 2020).

Despite the improvements witnessed in the health status in middle-income countries, it is still lower compared to high-income countries although it is higher than low-income countries. Although the gap is relatively small in life expectancy which reached 63.8 and 
80.7 years in low- and high-income countries in 2018, it has been larger in the mortality rates. The infant, neonatal and under-five mortality rates per 1,000 live births in low-income countries have reached 48.1, 26.4 and 68.1, while it reached 4.3, 2.8 and 5 in high-income countries in 2018. Also, the maternal mortality ratio have reached 462 and 11 in low- and high-income countries during the same year (World Bank, 2020).

Also, the gap has been wide in the prevalence of undernourishment and underweight where the former reached $28 \%$ and 3\% in low- and high-income countries in 2017 and the latter reached $18.5 \%$ and $0.9 \%$ in low- and high-income countries in 2018, respectively. However, middle-income countries have been capable of narrowing the gap with highincome countries in providing the population with access to basic drinking water services as the latter provided access to $99.5 \%$ of the population compared to $91 \%$ in the former in 2017 .

The situation was not different for the health-care workforce. Despite the advancements in the health-care workforce in middle-income countries where the number of physicians and the number of nurses and midwives per 1,000 people have slightly increased from 1.1 and 0.9 in 1990 to 1.4 in 2017 and 2.7 in 2018, respectively, it remained lower than high-income countries where the number of physicians and the number of nurses and midwives reached 3 in 2017 and 11 in 2018, respectively. However, the number of hospital beds per 1,000 people has declined from 3.1 in 1990 to 2.4 in 2011 in middle-income countries and which remained lower compared to high-income countries with a number of hospital beds of 4 per 1,000 people (World Bank, 2020).

Health-care financing has changed significantly where total expenditure on health-care as a percentage of GDP has been increasing at a higher pace than the increase in GDP where it reached $6 \%$ in middle-income countries compared to $4 \%$ in high-income countries. Also, despite the continuous increase in the general government health expenditure as a percentage of current health expenditure from $37 \%$ in 2000 to $51 \%$ in 2016, middle-income countries still suffer from high out-of-pocket expenditure per capita at purchasing power parity ( $\$ 237.8$ in 2016 compared to $\$ 136.9$ in 2006) which has a catastrophic impact on the poorest segments of the population due to the resulting pressure on their financial budgets and their inability to access the needed health-care services (Xu et al., 2018; World Bank, 2020).

The disease burden in middle-income countries has transformed from communicable to non-communicable diseases (NCDs) due to rapid globalization and urbanization, where the percentage of deaths due to NCDs has increased from around $60 \%$ in 2000 to $72 \%$ in 2015 . Also, the death rate among youth is increasing rapidly specifically among the poorest populations due to cardiovascular diseases, diabetes, cancer and chronic respiratory diseases (World Health Organization, 2010).

\section{Methods and data \\ Methods}

Stochastic Frontier Analysis (SFA) models were introduced in the seventies by Aigner et al. (1977), Battese and Corra (1977) and Meeusen and Van Den Broeck (1977) as one of the parametric techniques. Those models are used to evaluate the technical efficiency empirically, where the production function is assumed to take a certain shape and is then estimated to determine the frontier which is the empirical estimate of the ideal production. Individual observations, which fall below it, are compared relative to the frontier and to each other to evaluate the technical efficiency of different observations. In other words, the SFA is a benchmarking or a boundary method that allows the estimation of the level of efficient production taking into account the stochastic nature of the input data (Kulik, 2017).

Several model specifications have been introduced since then to measure the technical efficiency (Schmidt and Sickles, 1984; Battese and Coelli, 1995; Greene, 2005; Wang and Ho,
Technical
efficiency of
health-care
systems

273 
REPS

5,4

2010). The paper will use the generalized true random effects model introduced by Kumbhakar et al. in 2014 which overcomes the limitations of the earlier models. The model divides the error term into four parts, where the first part measures unobserved heterogeneity, the second measures transient or time-varying inefficiency, the third measures persistent or time-invariant inefficiency and the last measures random shocks. All the previous models were not able to capture all the four components of the error term; instead, they focused only on one or two of these components, which has left the inefficiency to be mixed up with unobserved heterogeneity and hence leading to mis-specified results.

The model takes the following form:

$$
y_{i t}=\alpha_{0}+f\left(x_{i t} ; \beta\right)+\mu_{i}+v_{i t}-\eta_{i}-u_{i t}
$$

where:

$y_{i t} \quad=$ represents output of firm i at time t;

$\alpha_{0} \quad=$ represents the intercept;

$f\left(x_{i t} ; \beta\right)=$ represents the production technology, where $x_{i t}$ represents the vector of inputs and $\beta$ represents the associated vector of parameters to be estimated;

$\mu_{i} \quad=$ represents the random firm effects that capture unobserved heterogeneity;

$v_{i t} \quad=$ represents the random error term;

$\eta_{i} \quad=$ represents persistent inefficiency; and

$u_{i t} \quad=$ represents transient inefficiency.

To estimate the model, the general form is reformulated as follows:

$$
y_{i t}=\alpha_{0}^{*}+f\left(x_{i t} ; \beta\right)+\alpha_{i}+\varepsilon_{i t}
$$

where:

$$
\begin{aligned}
& \alpha_{0}^{*}=\alpha_{0}-\mathrm{E}\left(\eta_{i}\right)-E\left(u_{i t}\right) \\
& \alpha_{i}=\mu_{i}-\eta_{i}+E\left(\eta_{i}\right) ; \text { with zero mean and constant variance } \\
& \varepsilon_{i t}=v_{i t}-u_{i t}+E\left(u_{i t}\right) ; \text { with zero mean and constant variance }
\end{aligned}
$$

The model can be estimated in three steps. In Step 1, the transformed model in [equation (1)] is estimated using fixed-effect or random-effect estimation where $\alpha_{0}^{*}, \beta, \alpha_{i}$ and $\varepsilon_{i t}$ are estimated. In Step 2, the estimated values of $\varepsilon_{i t}$ from Step 1 are used to estimate the timevarying inefficiency $\left(u_{i t}\right)$ through applying the standard stochastic frontier analysis technique to the previously introduced equation $\varepsilon_{i t}=v_{i t}-u_{i t}+E\left(u_{i t}\right)$; where $v_{i t}$ is i.i.d $\mathrm{N}(0$, $\left.\sigma_{v}^{2}\right)$ and $u_{i t}$ is i.i.d. $\mathrm{N}^{+}\left(0, \sigma_{u}^{2}\right)$. By the end of this step, both the transient inefficiency $\left(\hat{u_{i t}}\right)$ and the transient efficiency $\left(\exp \left(-\hat{u_{i t}}\right)\right)$ can be calculated using Jondrow et al. (1982) and Battese and Coelli (1988) procedures, respectively.

Similarly to Step 2, in Step 3, the estimated values of $\alpha_{i}$ from Step 1 are used to estimate the persistent inefficiency $\left(\eta_{i}\right)$ through applying the standard normal-half normal stochastic frontier analysis model to the previously introduced equation $\alpha_{i}=\mu_{i}-\eta_{i}+\mathrm{E}\left(\eta_{i}\right)$; where $\mu_{i}$ is i.i.d. $\mathrm{N}\left(0, \sigma_{u}^{2}\right)$ and $\eta_{i}$ is i.i.d. $\mathrm{N}^{+}\left(0, \sigma_{\eta}^{2}\right)$. By the end of this step, both the persistent inefficiency $\left(\hat{\eta}_{i}\right)$ and the persistent efficiency $\left(\exp \left(-\hat{\eta}_{i}\right)\right)$ can be calculated using Jondrow et al.(1982) and Battese and Coelli (1988) procedures, respectively.

Both transient and persistent efficiency and inefficiency ranges from 0 to 1 , where 0 illustrates the non-existence of efficiency/inefficiency and 1 illustrates that the firm is perfectly efficient/inefficient, respectively. Then, the total technical efficiency can be calculated through multiplying both the transient and persistent efficiency for each firm. 
Transient efficiency measures the short-term efficiency that changes over time and is related to the performance of the institutions working within the system. Persistent efficiency measures the long-term efficiency that does not change over time and is related to the structure and the policy design in the system (Agasisti and Gralka, 2017).

Technical
efficiency of
health-care
systems

275

\section{Data}

The SFA models analyse the health-care system from a production function perspective where the health output is the dependent variable and the inputs to the health-care system are the independent variables. Life expectancy at birth was chosen as the dependent variable. Life expectancy at birth measures the number of years a newborn would live if prevailing patterns of mortality at the time of his birth were to stay the same throughout his life. Although direct measurement of health at the macro level is not easy and there is no consensus among economists on the indicator that can be used to measure it, several studies have used life expectancy at birth as a measure of the health status (Tandon et al., 2001; Ravangard et al., 2014; Jayasuriya and Wodon, 2003; Frogner et al., 2015).

Regarding the independent variables, seven indicators have been chosen to capture the economic, social and environmental factors that affect the health status of the population. In this paper, the variables representing the economic factors are current health expenditure as a percentage of GDP, out-of-pocket expenditure per capita at purchasing power parity (PPP), food production index, current GDP per capita at purchasing power parity (PPP) and inflation rate. The social factor is represented by the education index in the human development index. The environmental factor is represented by urbanization.

Current health expenditure as a percentage of GDP has been chosen as an indicator that measures the importance of the health-care system to the society as a whole through illustrating the amount of financial resources directed toward the health-care sector relative to other sectors. Out-of-pocket expenditure per capita (PPP) is an indicator that measures the health expenditure capabilities and additional participation of the population as well as their effective usage of the health-care services.

Current GDP per capita (PPP) is an indicator of income relative to the population size. The food production index is a measure of food availability through covering food crops that are edible and contain nutrients. Income and food have been used by several studies as determinants of health production. Higher income allows individuals to purchase goods and services that enhance their health and allows the state to invest in better health technologies. Shortage of food intake leads to health problems and lowers the possibility of having a healthy life (Ogloblin, 2011; Fayissa and Gutema, 2005; Kabir, 2008; Halicioglu, 2010).

The inflation rate reflects the reduction in the purchasing power of money in an economy. High rates of inflation can affect life expectancy negatively through limiting the financial capability of the sick individuals (especially the elderly) who use their financial resources to cover the expenses of their daily living in addition to the expenditure on healthcare (Garcia et al., 2019).

The education index measures the level of educational attainment, and it is expected to have a positive impact on the health status, as higher educational levels enhance the people's ability to use health-care services more effectively. Urbanization which measures the percentage of population that lives in urban areas was chosen as an indicator of healthcare services accessibility as it measures the ability of the population to have better access to the basic living conditions (Koku, 2015; Aka and Dumont, 2008; Dhaoui, 2019).

Although there are other variables that affect the health output, such as the number of physicians, pollution, income inequality and life style (Hamidi and Akinci, 2016; 


\section{REPS}

5,4

\section{$276 \quad$ Results}

Bayati et al., 2013; De Cos and Moral-Benito, 2011), the choice of the input variables in that study has been based on data availability for the selected middle-income countries.

All data are annual data and were sourced for all the 21 countries during the period (2000-2017) from the World Development Indicators database except for the education index which was sourced from the Human Development database.

\section{Descriptive statistics}

As illustrated in Table 1, there is a great variation among the chosen countries in most of the selected indicators due to their heterogeneous nature. Regarding the health output (life expectancy), the gap is not so wide between countries, where it scored 71 years on average, with the minimum value of 53 years and the maximum value of 77 years and a coefficient of variation of $6.74 \%$.

As for the health inputs, the largest variation is mostly apparent in the inflation rate with a coefficient of variation of $98 \%$. Also, the gap is wide in the out-of-pocket expenditure per capita (PPP) with a coefficient of variation of $78 \%$ and a minimum value of $\$ 16.87$ and a maximum value of $\$ 799.15$, followed by $56 \%$ for the GDP per capita (PPP), $37 \%$ for the current health expenditure as a percentage of GDP, 33\% for the urbanization and $19 \%$ and $17 \%$ for the education index and the food production index, respectively.

\section{Stochastic frontier analysis and technical efficiency estimates}

Balanced cross-sectional time-series panel data of 21 middle-income countries over the period (2000-2017) has been used to evaluate the technical efficiency of their health-care systems. A production function in the form of Cobb-Douglas has been estimated using STATA 14 where the natural logarithmic of the dependent variable and the natural logarithmic of the independent variables (except the inflation rate [1]) have been used. The choice of the Cobb-Douglas function is in line with a variety of studies (Hamidi and Akinci, 2016; Koku, 2015; De Cos and Moral-Benito, 2011; Frogner et al., 2015).

As illustrated earlier, the model has been estimated in three steps. First, the model in equation (1) has been estimated using both the fixed effects and random effects, and by conducting the Hausman test, we could not reject the null hypothesis at $5 \%$ significance level; therefore, the random effects model has been chosen, and it was estimated using generalized least squares (Table 2).

Table 1.

Descriptive statistics of the output and input variables (2000-2017)

\begin{tabular}{lccrrr}
\hline Variable & Observations & Mean & SD & \multicolumn{1}{c}{ Min } & \multicolumn{1}{c}{ Max } \\
\hline $\begin{array}{l}\text { Life expectancy at birth } \\
\text { Current health }\end{array}$ & 378 & 71.04744 & 4.789948 & 52.567 & 77.305 \\
expenditure (\% of GDP) & 378 & 4.899846 & 1.808843 & 1.915698 & 11.79826 \\
Out-of-pocket expenditure & & & & & \\
per capita(PPP) & 378 & 192.1785 & 150.4752 & 16.87367 & 799.1506 \\
GDP per capita (PPP) & 378 & $10,976.48$ & $6,161.639$ & $1,346.743$ & $30,004.08$ \\
Food production index & 378 & 110.907 & 18.43197 & 66.13 & 164.91 \\
Inflation rate & 378 & 8.496084 & 8.287987 & -11.18979 & 52.92366 \\
Education index & 378 & 0.6043519 & 0.1126751 & 0.259 & 0.832 \\
Urbanization & 378 & 58.00841 & 18.94747 & 23.59 & 91.749 \\
& & & & &
\end{tabular}

Source: World Bank (2020) and United Nations Development Programme (2020) 
All the independent variables except urbanization and the inflation rate have a significant impact on life expectancy at 5\% significance level with the expected sign. The largest elasticity of health production represented by life expectancy is through education, where a $1 \%$ increase in the education index will lead to an increase in life expectancy with $0.08 \%$. GDP per capita (PPP) and the food production index have a positive impact on life expectancy, where a $1 \%$ increase in them leads to an increase in life expectancy with almost $0.04 \%$.

Although the current health expenditure as a percentage of GDP has a positive impact on life expectancy $(0.03 \%)$, the percentage increase in out-of-pocket expenditure per capita (PPP) leads to a decline in life expectancy with a percentage of $0.02 \%$.

In Step 2, the predicted values of $\varepsilon_{i t}$ from the previously estimated random effects model are used to estimate the transient inefficiency $\left(u_{i t}\right)$ using the standard stochastic frontier analysis. Table 3 shows both the transient efficiency and inefficiency calculated using the Battese and Coelli (1988) and Jondrow et al. (1982) procedures, respectively. It is apparent that the transient efficiency of the selected countries is very high (99.99\%), which means that the health-care systems in the selected countries had a high level of institutional efficiency in the health-care sector over the period (2000-2017).

Although the transient inefficiency for the 21 selected countries over the period (20002017) was minor, there has been slight changes in them during the study period. As shown in Figure 1, the transient inefficiency declined significantly in South Africa and Russia since 2005. While Vietnam, China, Indonesia, Malaysia and the Philippines have witnessed a slight increase in their transient inefficiency. It has been relatively constant in other countries, such as Egypt and Colombia.

In Step 3, the predicted values of $\alpha_{i}$ obtained from Step 1 are used to estimate the persistent inefficiency $\left(\eta_{i}\right)$ using the standard normal-half normal stochastic frontier analysis. Table 4 shows both the persistent efficiency and inefficiency using the Battese and Coelli (1988) and Jondrow et al. (1982) procedures, respectively.

\begin{tabular}{lrr}
\hline Variable & Estimate & SE \\
\hline Constant & $3.866456^{*}$ & 0.0790274 \\
Ln(current health expenditure (\% of GDP)) & $0.0324674^{*}$ & 0.0093601 \\
Ln(out-of-pocket expenditure per capita PPP) & $-0.0155378^{*}$ & 0.0046397 \\
Ln(GDP per capita PPP) & $0.0397739^{*}$ & 0.0069179 \\
Ln(food production index) & $0.0376565^{*}$ & 0.0106334 \\
inflation rate & -0.0001744 & 0.0001218 \\
Ln(education index) & $0.0794894^{*}$ & 0.0180888 \\
Ln(urbanization) & -0.018472 & 0.0186518
\end{tabular}

Technical efficiency of health-care systems

Note: ${ }^{*} p<0.05$

Table 2.

Random effects model: Estimation results

\begin{tabular}{lccccr}
\hline Variable & Observations & Mean & Min & Max & $\begin{array}{r}\text { Table 3. } \\
\text { Transient efficiency } \\
\text { Transient efficiency }\end{array}$ \\
Transient inefficiency & 378 & 0.999928 & 0.999927 & 0.9999295 & and inefficiency \\
(2000-2017)
\end{tabular}




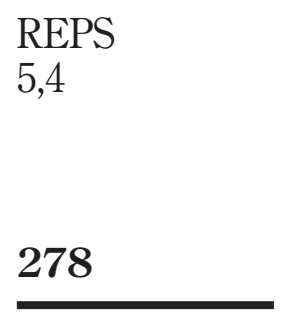

Figure 1.

Transient inefficiency (2000-2017)

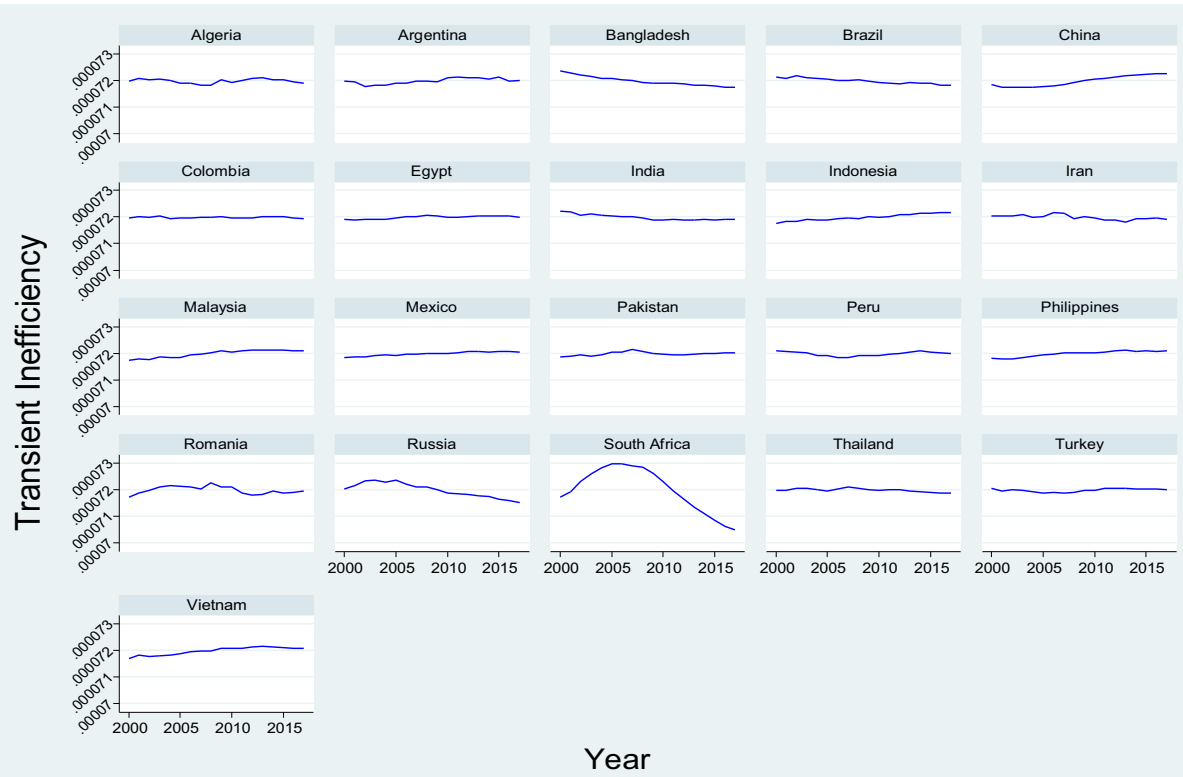

Table 4.

Persistent efficiency and inefficiency

(2000-2017)

\begin{tabular}{lccll}
\hline Variable & Observations & \multicolumn{1}{c}{ Mean } & \multicolumn{1}{c}{ Min } & \multicolumn{1}{c}{ Max } \\
\hline Persistent efficiency & 378 & 0.9377327 & 0.7176375 & 1 \\
Persistent inefficiency & 378 & 0.0664486 & $8.72 \mathrm{e}-15$ & 0.3317906
\end{tabular}

During the period of the study (2000-2017), the persistent efficiency of the selected countries was lower than the transient efficiency (93.8 vs $99.99 \%$ ). Vietnam is the only country which had no persistent inefficiency followed by the lowest levels in Mexico $(0.54 \%)$ and China $(0.66 \%)$, while the highest levels of persistent inefficiency were found in South Africa (33\%) and Russia (14\%) (Figure 2).

Comparing between transient and persistent efficiency in the 21 countries over the period (2000-2017) illustrates that Vietnam is the only country that is almost perfectly efficient in the short run and the long run. The gap between the transient and persistent efficiency is the lowest in Mexico and China, while the gap is the largest in South Africa and Russia (Figure 3).

The lower levels of persistent efficiency have led to lower levels of total technical efficiency, on average (Table 5). Also, the gap between the minimum and maximum values of persistent efficiency is large (0.72-1) compared to their counterparts of the transient efficiency (0.999927-0.9999295). Accordingly, this has led to a large gap between the minimum and the maximum values of the total technical efficiency $(0.7176-0.9999)$. The minimum value of the total technical efficiency was found in South Africa, while the maximum value was found in Vietnam (Figure 4). The mean total technical efficiency for the 21 countries during the period (2000-2017) is given in Figure A1. 


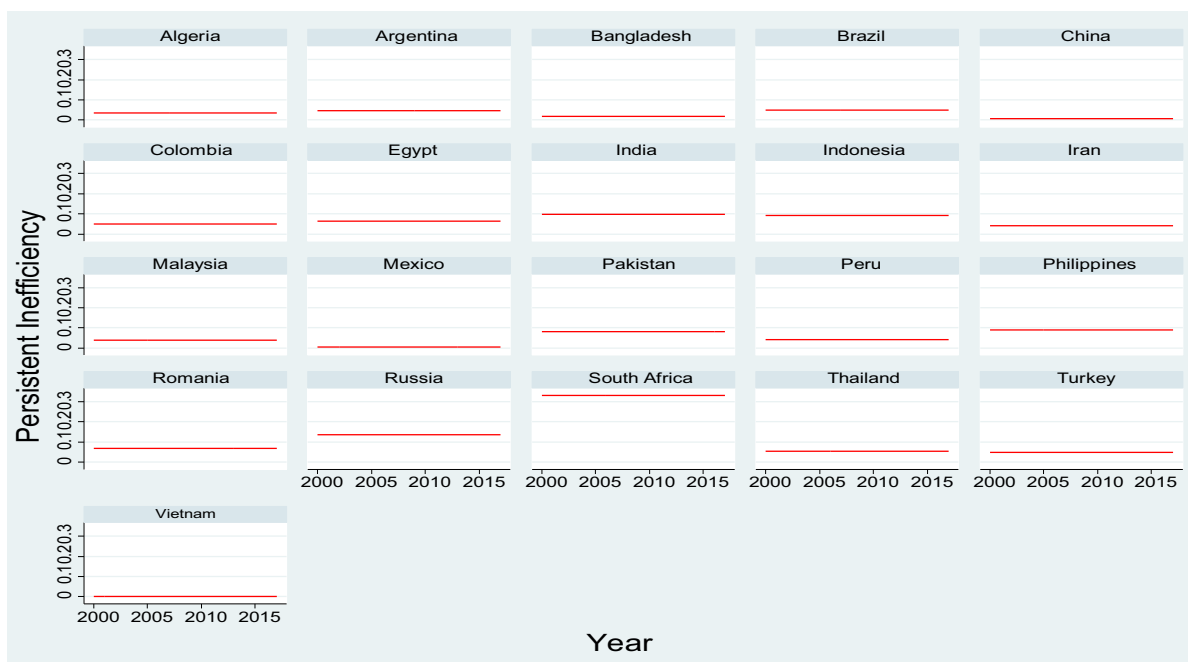

Technical efficiency of health-care systems

Figure 2.

Persistent inefficiency (2000-

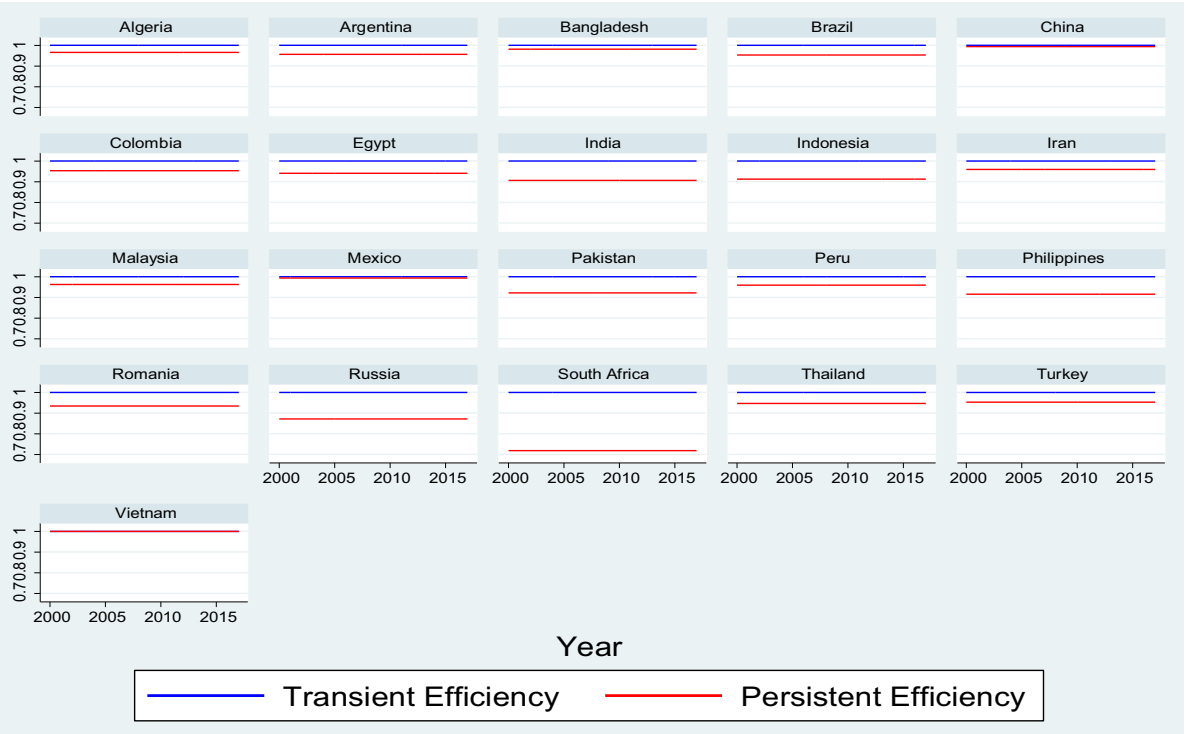

Figure 3. Transient and persistent efficiency (2000-2017)

\section{Discussion and conclusion}

Due to the importance of health-care for economic development and its sustainability, this paper has evaluated the technical efficiency of the health-care systems of 21 selected middleincome countries during the period (2000-2017). Evaluating the efficiency shall enable those countries to maximize the utilization of their resources in such a way that ensures the 
REPS

5,4

\section{0}

\section{Table 5.}

Transient, persistent and total technical efficiency (20002017) optimum allocation of the limited financial resources directed toward the health-care sector to satisfy the continuously increasing demands of the population.

Life expectancy at birth was used as the health output while current health expenditure as a percentage of GDP, out-of-pocket expenditure per capita (PPP), current GDP per capita (PPP), food production index, inflation rate, education index and urbanization were used as inputs. It was found out that urbanization and the inflation rate did not have a significant impact on life expectancy in contrast to all the other inputs.

This has two main implications. First, life expectancy is affected not only by expenditure on health-care but also by other socio-economic factors. Therefore, expenditure on healthcare should be directed toward cost-effective interventions and should be associated with adopting policies that aim at enhancing education and food production to ensure achieving efficiency in the production of health.

Second, although increasing both public and private expenditure on health-care will have a positive impact on life expectancy, an increase in out-of-pocket expenditure shall lead to a decline in life expectancy due to its negative impact on the equitable access of the population to health-care services through putting pressures on the income of the ill population.

\begin{tabular}{lcccc}
\hline Variable & Observations & \multicolumn{1}{c}{ Mean } & \multicolumn{1}{c}{ Min } & \multicolumn{1}{c}{ Max } \\
\hline Transient efficiency & 378 & 0.999928 & 0.999927 & 0.9999295 \\
Persistent efficiency & 378 & 0.9377327 & 0.7176375 & 1 \\
Total technical efficiency & 378 & 0.9376652 & 0.7175852 & 0.9999283 \\
\hline
\end{tabular}

Figure 4.

Total technical efficiency (20002017)

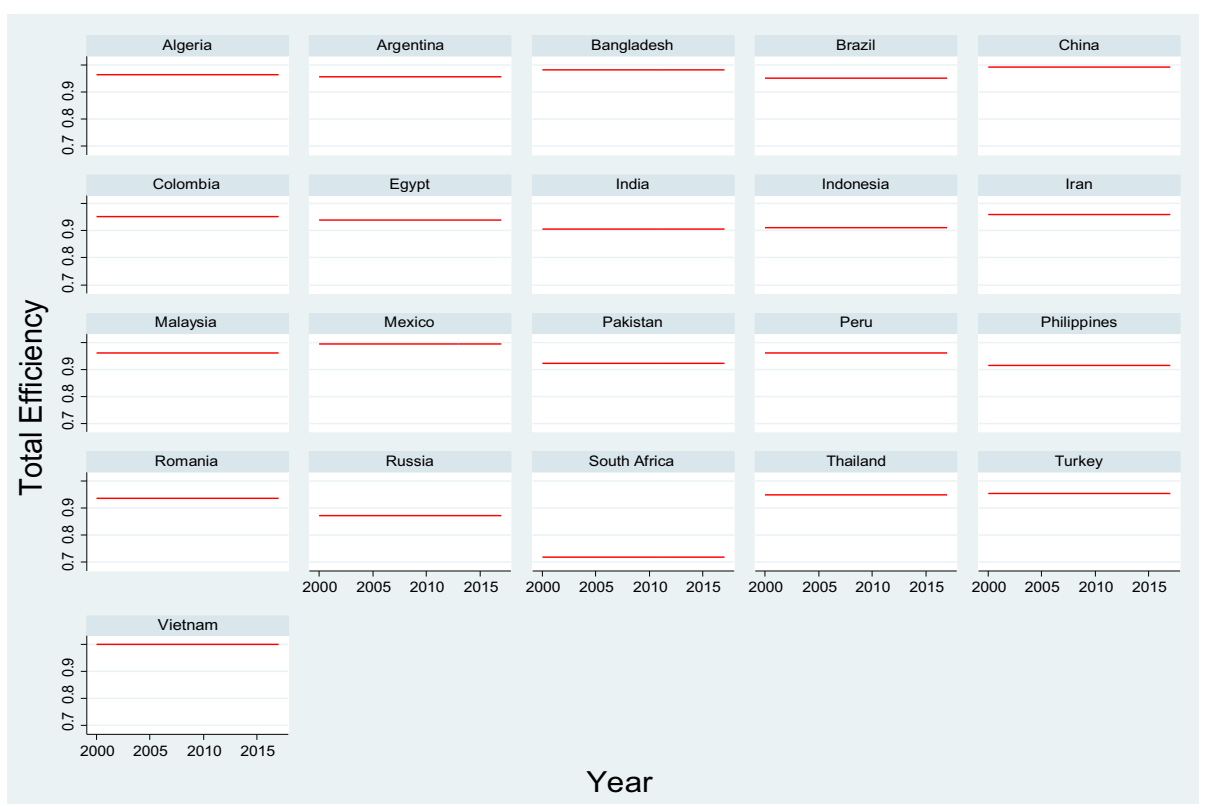


Also, we have estimated the technical efficiency and divided it into persistent and transient efficiency. During the period (2000-2017), the persistent efficiency was found to be lower than the transient efficiency. This means that inefficiency is inherent in the long-term structure of the health-care systems of the 21 countries, and it is related to policy adoption in the health-care sector. However, the individual institutions working in the health-care sector were able to perform efficiently as illustrated by the high level of transient efficiency. Accordingly, more effort needs to be exerted by those countries to improve the health-care structure and adopted policies to reduce their persistent inefficiency.

By examining the total technical efficiency of the 21 countries, it is found that Vietnam, Mexico and China are considered to be the most efficient countries with a score of (1), (0.995) and (0.993), respectively, while the least efficient countries are South Africa (0.718), Russia (0.872) and India (0.906). This illustrates that the 21 middle-income countries are reasonably operating at a relatively high level of efficiency on average, although there are still potential gains that can be made by those countries.

By examining the structure and policy adoption in the health-care systems of Vietnam, Mexico and China to determine how other countries can benefit from their experience, we found out that they succeeded in adopting a social health insurance that covers more than $85 \%$ of the population in addition to adopting strategies that ensured increasing the access to health-care services among the poor.

In 2018, the social health insurance coverage has reached $87 \%$ in Vietnam, where the poor, ethnic minority, children under six years, the elderly (above 80) and the socially vulnerable groups were fully covered through payment of the insurance premium by the government (World Health Organization, 2019).

There is a single compulsory insurance scheme in Vietnam which consists of three programs: social health insurance, health-care for the poor and free health-care for children under six years. To ensure that all segments of the population have access to health-care services, there are voluntary schemes that cover peasants, the self-employed and students (Le et al., 2010).

Mexico was capable of achieving near-universal health insurance coverage where $89 \%$ of the population were covered by health insurance. There are two main schemes of health insurance in Mexico, the first is the Mexican social security institute which cover government employees, private-sector workers, salaried workers and their respective families (Statista, 2019).

The system for social health protection is the second scheme which manages several programs such as catastrophic health expenditure, the 21st century medical insurance and the popular health insurance system that aims at covering the rest of the population (informal employees, the poor, self-employed, unemployed and children under five years), ensuring equitable access to health-care services and eliminating the financial burden on individuals with critical and chronic illnesses. In addition to that, there are separate insurance schemes for the armed forces, the state oil company and the navy (UrquietaSalomon and Villarreal, 2016; Lazano and Garrido, 2015).

Similar policies were adopted in China through its two main insurance schemes allowing for coverage of almost the whole population (more than 90\%), which are the urban employee basic medical insurance scheme covering the urban employees and retired individuals; and the urban rural resident basic medical insurance scheme covering the unemployed and the self-employed individuals in urban areas in addition to the rural population.

Other supplementary programs were adopted to ensure access to health-care services by the poor and individuals with severe illnesses through the medical aid program, catastrophic medical insurance and the critical illness insurance. This has led to a decline in
Technical efficiency of health-care systems

281 
REPS

5,4

282

out-of-pocket expenditure as a percentage of total health expenditure from $56 \%$ in 2003 to $29 \%$ in 2017 (Fang et al., 2019).

Also, more public resources were directed toward health-care which were used to upgrade the infrastructure of the health-care sector, renovate the primary health-care centers and increase the number of health-care workers.

In addition to that, decentralization has played an important role in those countries in ensuring that health-care services are provided to both rural and urban areas alike. Decentralization enabled the local communities to participate in the decision-making process through determining their needs and accordingly setting up their goals and deciding how funds should be allocated to achieve those goals and satisfy the needs of the population.

In Vietnam, there are four main levels which are responsible for the provision of healthcare services through hospitals, clinics, research institutes, university hospitals and health centers. The Ministry of Health comes in the first level through its responsibility in managing national budgets to priority areas and setting long-term plans and policies. In the second level is the provincial and municipal health facilities, which receive technical assistance from the Ministry of Health and determine the local goals and priorities and the way through which the funds should be allocated among them.

In the third and fourth levels are the district and communal health centers that provide services in districts and villages and that are managed by the provincial health facilities. Communal health centers are responsible for the provision of basic health-care services related to maternal and child health-care, immunization and family planning (Netherlands Enterprise Agency, 2019).

The situation in Mexico is similar to the situation in Vietnam, where the central government is responsible for designing health-care policies and regulations, making investment decisions in the health-care sector and providing secondary and tertiary healthcare services. As for the states, they are responsible for the provision of primary health-care services, prevention of communicable diseases and the organization and operation of healthcare institutions and services. In addition to that, the states are allocated with the HealthCare Services Contributions Fund (FASSA) to finance expenditure on health-care for the uninsured. Thus, it can be said that the states were given the necessary operative, economic, physical and human resources to have complete autonomy in the organization, finance and provision of health-care services (Arredondo and Orozco, 2006; Fritscher and Zamora, 2016).

Also, China has adopted decentralization where the central government is responsible for making policies for the country as a whole, while the local government is responsible for implementing those policies and financing them in a way that is suitable for the conditions of the local area and that satisfies the needs of the population in those areas. In addition to that, a multi-sector approach is adopted where five main bodies (the National Development and Reform program, Ministry of Finance, Ministry of Human Resources and Social Security, Ministry of Civil Affairs and Ministry of Commerce) participate with the Ministry of Health in the health-care system development and reform (Hu et al., 2013; Meng et al., 2004).

Although there is no-one size fits all policy recommendation due to the diverse economic, political and social conditions of the different middle-income countries, efficiency gains can be made by those countries through adopting long-term policies that ensure access of the whole population to health-care services, especially the poor and those who suffer from chronic illnesses in addition to adopting policies that allow different stakeholders in the health-care system to participate in the health-care policy making process on both the central and local levels. This shall guarantee that the adopted policies will satisfy the needs of the population, allow for equitable access to health-care services and lowers the burden of out-of-pocket expenditure on the population. 
Also, it is worth mentioning that the most efficient countries would not have been able to reach that high level of efficiency if it was not for their continuous efforts in monitoring and evaluating the outcomes of the adopted policies and comparing them with their pre-defined targets to ensure that they are moving in the right path and once there was a deviation, they adopted policies that would assist them in reaching their objectives.

Similar to previous studies that evaluated the technical efficiency of health-care systems, there are some limitations to our study. There might be a possibility of omitted variable bias due to the simplicity of the empirical model used. Also, the inputs used in this study were chosen based on data availability and their impact on health production; however, they are only proxies for economic, social and environmental factors. Thus, there might be other inputs that have a more direct impact on health production, such as the number of physicians and the number of hospital beds, but have not been included in our study due to data limitations.

\section{Note}

1. Due to having negative values in some years.

\section{References}

Agasisti, T. and Gralka, S. (2017), The Transient and Persistent Efficiency of Italian and German Universities: A Stochastic Frontier Analysis, CEPIE working paper no.14/17, Technische Universitat Dresden.

Aigner, D., Lovell, C. and Schmidt, P. (1977), "Formulation and estimation of stochastic frontier production function models", Journal of Econometrics, Vol. 6 No. 1, pp. 21-37.

Aka, B. and Dumont, J. (2008), "Health, education and economic growth: Testing for long-run relationships and causal links", Applied Econometrics and International Development, Vol. 8 No. 2, pp. 101-113.

Amponsah, S. and Amanfo, S. (2016), "Efficiency and productivity growth in the health care systems of Ghana: Regional comparison analysis using DEA",

Arredondo, A. and Orozco, E. (2006), "Effects of health decentralization, financing and governance in Mexico", Revista de Saúde Pública, Vol. 40 No. 1, pp. 152-160.

Asandului, L., Roman, M. and Fatulescu, P. (2014), "The efficiency of healthcare systems in Europe: a data envelopment analysis approach", Procedia Economics and Finance, Vol. 10, pp. 261-268.

Battese, E. and Coelli, T. (1988), "Prediction of firm level technical inefficiencies with a generalized frontier production function and panel data", Journal of Econometrics, Vol. 38 No. 3, pp. 387-399.

Battese, G. and Coelli, T. (1992), "Frontier production functions, technical efficiency and panel data: with application to paddy farmers in India", Journal of Productivity Analysis, Vol. 3 Nos 1/2, pp. 153-169.

Battese, G.E. and Coelli, T.J. (1995), “A model for technical inefficiency effects in a stochastic production function for panel data", Empirical Economics, Vol. 20 No. 2, pp. 325-332.

Battese, G. and Corra, G. (1977), "Estimation of a production frontier model: with application to the pastoral zone of Eastern Australia”, Australian Journal of Agricultural Economics, Vol. 21 No. 3, pp. 169-179.

Bayati, M., Akbarian, R. and Kavosi, Z. (2013), "Determinants of life expectancy in Eastern Mediterranean region: a health production function", International Journal of Health Policy and Management, Vol. 1 No. 1, pp. 57-61. 


\section{REPS \\ 5,4}

Chirikos, T. (1998), "Identifying efficiently and economically operated hospitals: the prospects and pitfalls of applying frontier regression techniques", Journal of Health Politics, Vol. 23 No. 6, pp. 879-904.

Colombi, R., Martini, G. and Vittadini, G. (2017), "Determinants of transient and persistent hospital efficiency: the case of Italy", Health Economics, Vol. 26 No. S2, pp. 5-22.

Cylus, J., Papanicolas, I. and Smith, P. (2016), "A framework for thinking about health system efficiency", in Cylus, J., Papanicolas, I. and Smith, P. (Eds), Health System Efficiency: How to Make Measurement Matter for Policy and Management, World Health Organization, United Kingdom, pp. 1-20.

De Cos, P. and Moral-Benito, E. (2011), Health Care Expenditure in the OECD Countries: Efficiency and Regulation, Occasional paper series no.1107, Banco De Espana, Madrid, Spain.

Dhaoui, I. (2019), Healthcare System Efficiency and Its Determinants: A Two-Stage Data Envelopment Analysis (DEA) from MENA Countries, Economic Research Forum, Arab Republic of Egypt.

Fang, H., Eggleston, K., Hanson, K. and Wu, M. (2019), "Enhancing financial protection under China's social health insurance to achieve universal health coverage", BMJ, Vol. 365, pp. 1-4.

Fayissa, B. and Gutema, P. (2005), "Estimating a health production function for Sub-Saharan Africa (SSA)", Applied Economics, Vol. 37 No. 2, pp. 155-164.

Fritscher, A. and Zamora, C. (2016), "An evaluation of the 1997 expenditure decentralization reform in Mexico: the case of the health sector", Public Finance Review, Vol. 44 No. 5, pp. 563-588.

Frogner, B., Frech, H. III. and Parente, S. (2015), "Comparing efficiency of health systems across industrialized countries: a panel analysis", BMC Health Services Research, Vol. 15 No. 1, pp. 415-426.

Garcia, L., Rabago, S. and Ocat, J. (2019), "Predictive capacity of country inflation rate to life expectancy at birth", International Journal of Advanced and Applied Sciences, Vol. 6 No. 12, pp. 67-70.

Gerdtham, U., Löthgren, M., Tambour, M. and Rehnberg, M. (1999), "Internal markets and health care efficiency: a multiple-output stochastic frontier analysis", Health Economics, Vol. 8 No. 2, pp. 151-164.

Greene, W. (2005), "Reconsidering heterogeneity in panel data estimators of the stochastic frontier model", Journal of Econometrics, Vol. 126 No. 2, pp. 269-303.

Grosskopf, S., Self, S. and Zaim, O. (2006), "Estimating the efficiency of the system of healthcare financing in achieving better health", Applied Economics, Vol. 38 No. 13, pp. 1477-1488.

Halicioglu, F. (2010), Modelling Life Expectancy in Turkey, MPRA paper no.30840, Department of Economics, Yeditepe University, Turkey.

Hamidi, S. and Akinci, F. (2016), "Measuring efficiency of health systems of the Middle East and North Africa (MENA) region using stochastic frontier analysis", Applied Health Economics and Health Policy, Vol. 14 No. 3, pp. 337-347.

Hofler, R. and Rungeling, B. (1994), "US nursing homes: are they cost efficient?", Economics Letters, Vol. 44 No. 3, pp. 301-305.

Hollingsworth, B. and Wildman, J. (2003), "The efficiency of health production: re-estimating the WHO panel data using parametric and non- parametric approaches to provide additional information", Health Economics, Vol. 12 No. 6, pp. 493-504.

Hu, S., Ljungwall, C. and Wikstrom, M. (2013), “China's Healthcare system-Overview and Quality Improvements", Swedish Agency for Growth Policy Analysis, Switzerland.

Ibrahim, M. and Daneshvar, S. (2018), "Efficiency analysis of healthcare system in Lebanon using modified data envelopment analysis", Journal of Healthcare Engineering, Vol. 2018, pp. 1-6.

Jayasuriya, R. and Wodon, Q. (2003), "Measuring and explaining country efficiency in improving health and education indicators", in Jayasuriya, R. and Wodon, Q. (Eds), Efficiency in Reaching the Millennium Development Goals, The World Bank, Washington, DC, pp. 5-16. 
Jondrow, J., Lovell, C., Materov, T. and Schmidt, P. (1982), "On the estimation of technical inefficiency in the stochastic frontier production model", Journal of Econometrics, Vol. 19 Nos 2/3, pp. 233-238.

Kabir, M. (2008), "Determinants of life expectancy in developing countries", The Journal of Developing Areas, Vol. 41 No. 2, pp. 185-204.

Karpa, W. and Leśniowska, J. (2014), "Efficiency of health care systems: stochastic frontier analysis including innovation component", Prace Naukowe Akademii im. Jana Dtugosza w Czestochowie. Pragmata Tes Oikonomias, Vol. 1 No. 8, pp. 159-167.

Kathuria, V. and Sankar, D. (2005), "Inter-state disparities in health outcomes in rural India: an analysis using a stochastic production frontier approach", Development Policy Review, Vol. 23 No. 2, pp. 145-163.

Kim, Y. and Kang, M. (2014), "The measurement of health care system efficiency: cross-country comparison by geographical region”, The Korean Journal of Policy Studies, Vol. 29 No. 1, pp. 21-44.

Koku, A. (2015), "Efficiency of government expenditure in the ECOWAS Sub-region”, Master thesis, University Of Ghana, Ghana.

Kooreman, P. (1994), "Nursing home care in The Netherlands: a nonparametric efficiency analysis", Journal of Health Economics, Vol. 13 No. 3, pp. 301-316.

Kulik, J. (2017), "Technical efficiency and the methods of its measurement”, Ekonometria, Vol. 3 No. 57, pp. $72-87$.

Kumbhakar, S., Lien, G. and Hardaker, J. (2014), "Technical efficiency in competing panel data models: a study of Norwegian grain farming", Journal of Productivity Analysis, Vol. 41 No. 2, pp. 321-337.

Lazano, R. and Garrido, F. (2015), "Improving Health System Efficiency Mexico: Catastrophic Health Expenditure Fund", World Health Organization, Switzerland.

Le, D., Kubo, T., Fujino, Y. and Pham, T. (2010), "Health care system in Vietnam: current situation and challenges", Asian Pacific Journal of Disease Management, Vol. 4 No. 2, pp. 23-30.

Lo, J., Shih, K. and Chen, K. (1996), "Technical efficiency of the general hospitals in Taiwan: an application of DEA", Academia Economic Papers, Vol. 24 No. 3, pp. 275-296.

Lovell, C. (1993), "Production frontiers and productive efficiency", in Fried, H.O., and Schmidt S.S. (Eds), The Measurement of Productive Efficiency, Oxford University Press, New York, NY, pp. 3-67.

McIntyre, D. (2007), Learning from Experience: health Care Financing in Low-and Middle-Income Countries, Global Forum for Health Research, Geneva.

Magnussen, J. (1996), "Efficiency measurement and the operationalization of hospital production", Health Services Research, Vol. 31 No. 1, pp. 21-37.

Medeiros, J. and Schwierz, C. (2015), "Efficiency estimates of health care systems", Economic Papers 549, European Commission.

Meeusen, W. and Van den Broeck, J. (1977), "Efficiency estimation from Cobb-Douglas production function with composed error", International Economic Review, Vol. 18 No. 2, pp. 435-444.

Meng, Q., Shi, G., Yang, H., Gonzalez-Block, M. and Blas, E. (2004), Health Policy and Systems Research in China, World Health organization, Switzerland.

Mirmirani, S. and Lippmann, M. (2004), "Health care system efficiency analysis of G12 countries", International Business and Economics Research Journal, Vol. 3 No. 5, pp. 35-42.

Netherlands Enterprise Agency (2019), Market Study: Opporunities for the Dutch Life Sciences and Health Sector in Vietnam, Task Force Health Care, The Netherlands.

Novignon, J. and Lawanson, A. (2014), Efficiency of Health Systems in Sub-Sahara Africa: A Comparative Analysis of Time Varying Stochastic Frontier Models, MPRA paper no. 56897, University Library of Munich, Germany.

Ogloblin, C. (2011), "Health care efficiency across countries: a stochastic frontier analysis", Applied Econometrics and International Development, Vol. 11 No. 1, pp. 5-14. 
REPS

5,4

Popescu, C., Asandului, L. and Fatulescu, P. (2014), “A data envelopment analysis for evaluating Romania's health system”, Procedia - Social and Behavioral Sciences, Vol. 109, pp. 1185-1189.

Ravangard, R., Hatam, N., Teimourizad, A. and Jafari, A. (2014), "Factors affecting the technical efficiency of health systems: a case study of economic cooperation organization (ECO) countries (2004-2010)", International Journal of Health Policy and Management, Vol. 3 No. 2, pp. 63-69.

Ryltseva, A. (2010), "Determinants of health status and the differences in efficiency of the utilization of health care inputs in countries of the former Soviet Union", Master Thesis, Central European University, Hungary.

Schmidt, P. and Sickles, R. (1984), "Production frontiers and panel data", Journal of Business and Economic Statistics, Vol. 2 No. 4, pp. 367-374.

Statista (2019), "Number of population with health insurance in Mexico in 2018, by type of institution or program (in millions)", Retrieved from: www.statista.com/statistics/1043261/mexico-numberpopulation-health-insurance-type/

Street, A. and Jacobs, R. (2002), "Relative performance evaluation of the English acute hospital sector", Applied Economics, Vol. 34 No. 9, pp. 1109-1119.

Tandon, A., Murray, C., Lauer, J. and Evans, D. (2001), The Comparative Efficiency of National Health Systems in Producing Health: An Analysis of 191 Countries, GPE Discussion Paper no. 29, World Health Organization, Switzerland.

United Nations Development Programme (2020), "Human development data (1990-2018)", Retrieved from: http://hdr.undp.org/en/data

Urquieta-Salomon, J. and Villarreal, H. (2016), "Evolution of health coverage in Mexico: evidence of progress and challenges in the Mexican health system", Health Policy and Planning, Vol. 31 No. 1, pp. 28-36.

Wagstaff, A. (1989), "Estimating efficiency in the hospital sector: a comparison of three statistical cost frontier models", Applied Economics, Vol. 21 No. 5, pp. 659-672.

Wang, H. and Ho, C. (2010), "Estimating fixed-effect panel stochastic frontier models by model transformation", Journal of Econometrics, Vol. 157 No. 2, pp. 286-296.

World Bank (2020), "The world development indicators", Retrieved from: https://datacatalog. worldbank.org/dataset/world-development-indicators

World Health Organization (2000), The World Health Report 2000-Health Systems: improving Performance, World Health Organization, Geneva.

World Health Organization (2010), Non-Communicable Diseases in Low and Middle-Income Countries, Background paper, Regional High-level Consultation in the Eastern Mediterranean Region on the Prevention and Control of Non-communicable Diseases in Low- and Middle-Income Countries, Islamic Republic of Iran, Tehran.

World Health Organization (2019), "Health financing in Vietnam", Retrieved from: www.who.int/ vietnam/health-topics/health-financing.

Xu, K., Soucat, A. and Kutzin, J. (2018), Public Spending on Health: A Closer Look at Global Trends, HF working paper, World Health Organization, Switzerland.

Zuckerman, S., Hadley, J. and Iezzoni, L. (1994), "Measuring hospital efficiency with frontier cost functions", Journal of Health Economics, Vol. 13 No. 3, pp. 255-280. 
Least efficient

Most efficient

Source: Drawn by the authors
Figure A1. Mean total technical efficiency during the period (2000-2017)

\section{Corresponding author}

Pakinam Fikry can be contacted at: pakinam_fikry@feps.edu.eg

For instructions on how to order reprints of this article, please visit our website: www.emeraldgrouppublishing.com/licensing/reprints.htm Or contact us for further details: permissions@emeraldinsight.com 